\title{
Properties of Starch Based Foams Made by Thermal Pressure Forming
}

\author{
J. Štancl, J. Skočilas, J. Šesták, R. Žitný
}

Packaging materials based on expanded polystyrene can be substituted by biodegradable foam, manufactured by direct or indirect electrical heating of a potato starch suspension in a closed mold. This paper deals with an experimental evaluation of selected properties of potato starch and starch foam related to this technology: density, specific heat capacity and specific electrical conductivity of a water suspension of potato starch within the temperature range up to $100^{\circ} \mathrm{C}$, and mass fraction from 5 to $65 \%$. The electric conductivity and heat capacity changes were observed during direct ohmic heating of a starch suspension between electrodes in a closed cell (feeding voltage $100 \mathrm{~V}$, frequency $50 \mathrm{~Hz}$ ). Specific electric conductivity increases with temperature, with the exception of the gelatinization region at 60 to $70{ }^{\circ} \mathrm{C}$, and decreases with increasing concentration of starch (the temperature and concentration dependencies were approximated using the Lorentz equation). Direct ohmic heating is restricted by a significant decrease in effective electrical conductivity above a temperature of $100{ }^{\circ} \mathrm{C}$, when evaporated steam worsens the contact with the electrodes. Experiments show that when direct ohmic heating is not combined with indirect contact heating, only $20 \%$ of the water can be evaporated from manufactured samples and the starch foam is not fully formed. This is manifested by only a slight expansion of the heated sample. Only the indirect contact heating from the walls of the mold, with the wall temperature above $180^{\circ} \mathrm{C}$, forms a fixed porous structure (expansion of about $300 \%$ ) and a crust, ensuring suitable mechanical and thermal insulation properties of the manufactured product. The effective thermal conductivity of the foamed product (sandwich plates with a porous core and a compact crust) was determined by the heated wire method, while the porosity of the foam and the thickness of the crust were evaluated by image analysis of colored cross sections of manufactured samples. While the porosity is almost constant, the thickness of the crust is approximately proportional to the thickness of the plate.

Keywords: starch, starch suspension, starch foam, direct ohmic heating, indirect heating, electric conductivity of a starch suspension.

\section{Introduction}

Thermally or pressure formed starch based materials can be used in the packaging industry for manufacturing dishes, cups, containers, as a substitute for petroleum based plastics, especially expanded polystyrene. Packaging materials manufactured from starch compost easily in nature, and are biodegradable. These products are manufactured by extraction, extrusion, high pressure compression (explosion), see Glenn et al. [1], or by heating starch suspensions in closed molds. This process is similar to baking a dough, but at a higher pressure. The process includes not only one-phase heating of a liquid suspension, but also the formation of steam bubbles accompanied by sample expansion and the formation of a crust. Mathematical modeling of the process requires knowledge of density, heat capacity, thermal conductivity, enthalpy of evaporation; see Zanoni et al. [2], Wang and Hayakawa [3], Maroulis et al. [4]. Sorption isotherms for potato starches were presented by Lind and Rask [5], Cha et al. [6] and some rheological properties of liquid matrix can be found in Schwarzberg [7], Wang [8] and Lagarrigue [9]. It should be noted that the data presented in these references is restricted to a narrow range of concentrations and temperatures.

A disadvantage of the process is the long heating time, which can be reduced by combining classical contact heating from hot walls with volumetric heating, for example by using microwave or direct ohmic heating. The aim of this paper is to evaluate the most important parameter for direct ohmic heating, which is the effective electric conductivity of the processed sample. Overall conductivity is affected by the specific electric conductivity of the starch suspension and by the contact resistance at the contact with the electrodes of the heating apparatus. Little information is available on these properties for starch based systems, see Wang and Sastry [8]. Their work is restricted to a low concentration of potato starch (up to 0.2, and the electric conductivity of the water suspension is artificially increased by $\mathrm{NaCl}$ ) and temperatures below $90^{\circ} \mathrm{C}$.

The functional properties of the manufactured products are determined by their mechanical properties (strength), see Glenn et al. [1], stability and resistance (permeability and absorptiveness), and thermal insulation properties. The most important characteristics affecting these properties are the effective thermal conductivity, porosity and thickness of the crust. Scanning electron micrographs of baked starch foams are presented by Shogren et al. [10], and some selected properties of crust are discussed by Zanoni [11].

\section{Thermodynamic parameters of starch suspension}

The potato starch used in the experiments with thermal pressure formation reported by Skocilas et al. [12] and also for evaluating the electrical properties of starch suspensions presented in this paper, is commercially available Solamyl and Naturamyl powder, produced by Natura, Czech Republic. The composition of the powder and basic thermodynamic parameters of the water suspension are summarized in Table 1 .

It should be noted that the data presented in Table 1 is not sufficient for a full description of starch under typical conditions of thermal forming, where temperatures change from room temperature up to $180{ }^{\circ} \mathrm{C}$, and the moisture content decreases from approximately $50 \%$ almost to zero. Some properties change abruptly during gelatinization at about $70{ }^{\circ} \mathrm{C}$, and significant changes in rheological properties occur at the glass transition temperature of about $180^{\circ} \mathrm{C}$, affecting the formation of the crust. It is important to note that starch 
Table 1: Thermodynamic properties of the potato starch suspension

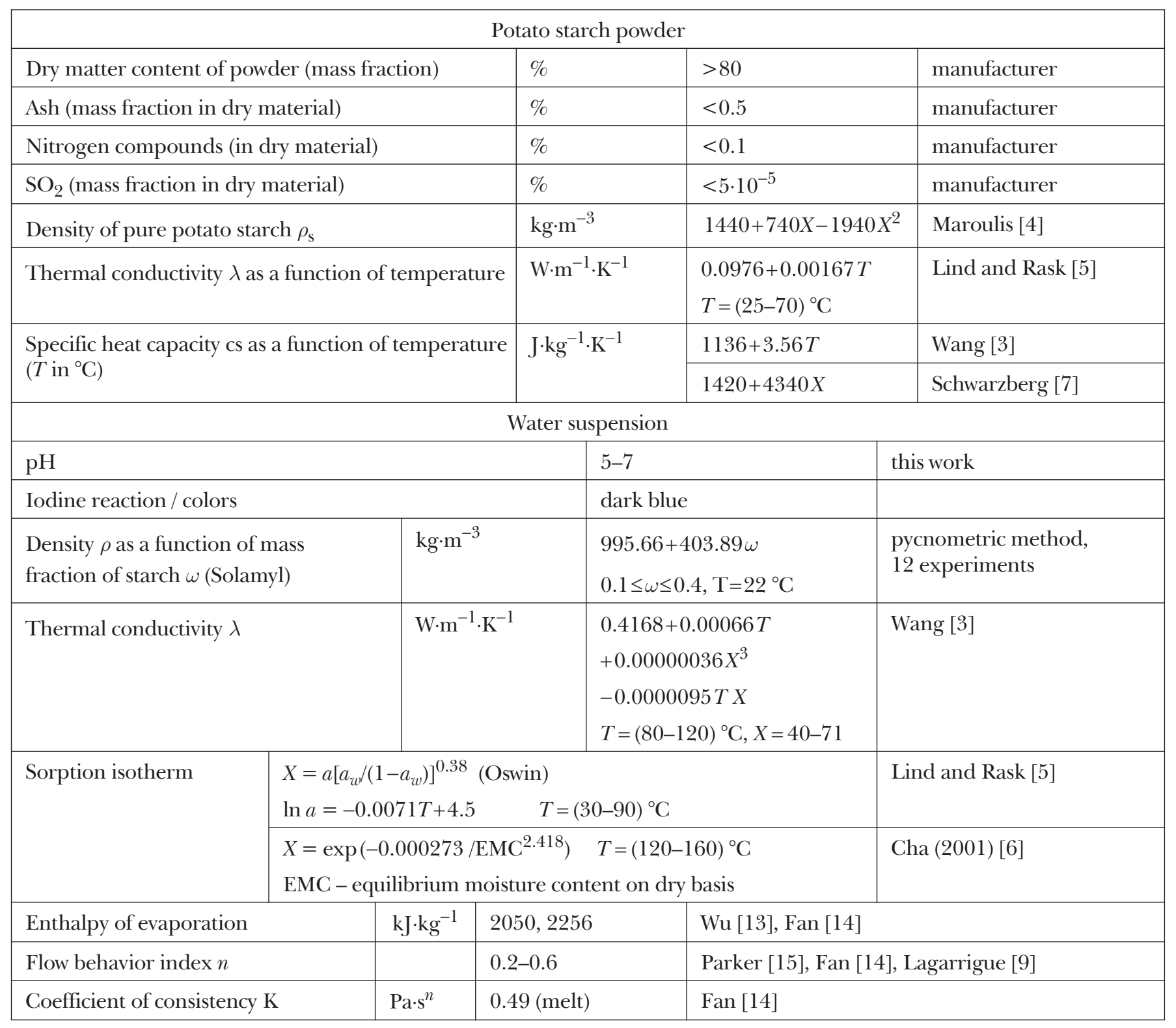

and starch-water systems are not homogeneous materials, and starch powder consists in fact of starch grains of typically $50 \mu \mathrm{m}$ in size (the distribution for potato starch consists of grains from 10 to $100 \mu \mathrm{m})$. This is important for the formation of steam bubbles, because grains in a water suspension play the role of nucleation centers.

\section{Direct ohmic heating and the electric properties of a potato starch suspension}

The process time necessary for heating a starch suspension inside a closed mold can be reduced by volumetric heating, for example making use of an electric current passing through a sample compressed between two electrodes (in reality, volumetric heating has to be combined with indirect contact heating, because only then is it possible to create a crust, ensuring desirable mechanical properties of the prod- uct). Accelerated ohmic heating is possible only if there are ions passing an electric charge through the sample. Their presence and mobility is manifested by positive specific electrical conductivity $\kappa$ of the heated material, depending upon the composition of the starch suspension and the temperature. Specific electrical conductivity $\kappa$ is easily measurable in liquids, but for example during gelatinization, accompanied by volumetric changes, standard conductivity probes cannot be applied. It should also be taken into account that standard instruments apply rather high feeding frequencies, and the results need not be directly applicable to industrial processes at much lower frequencies $(50-60 \mathrm{~Hz})$.

Different instruments were therefore used for a low concentration of Naturamyl potato starch mixed with tap water (mass fraction of starch from 0.05 up to 0.35 ) and for high concentrations (mass fraction from 0.55 to 0.65 ), when the mixture has the consistency of a viscous paste. The experimental setup is shown in Fig. 1. 


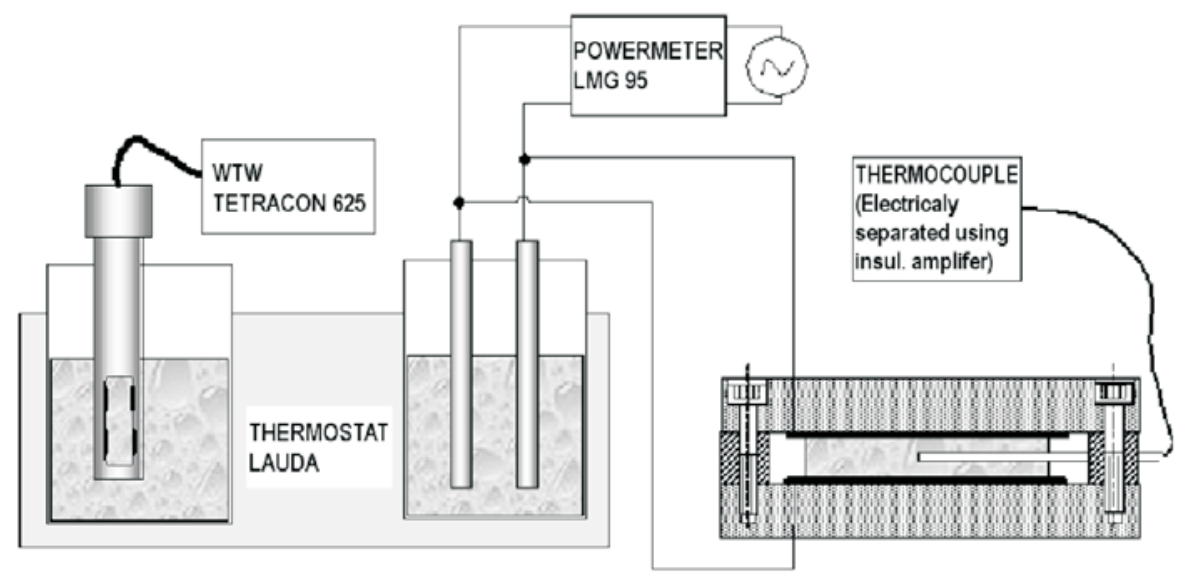

Fig. 1: Experimental setup for measuring the specific electrical conductivity of a starch suspension

In the low concentration range, the two cylindrical graphite electrodes (see Fig. 1) were submerged to a homogenized starch suspension and the electric current I, together with a small applied voltage $U$ (frequency $50 \mathrm{~Hz}$ ), were recorded by a powermeter (LMG 95, Zimmer Electronic Systems). The specific electrical conductivity was evaluated from

$$
\kappa=C \frac{I}{U},
$$

where $C$ is a calibration constant, evaluated for a fixed geometry of the cylindrical electrodes by comparison with results obtained by a WTW conductometer with a Tetracon 625 four-electron probe. This comparison was performed with water and for very low concentrations of starch at temperatures under $60^{\circ} \mathrm{C}$. This calibration constant $C$ was applied for a series of steady state experiments with graphite electrodes at temperatures (20-90) ${ }^{\circ} \mathrm{C}$ and for mass fractions of starch $0.05,0.15,0.25,0.35$. The results show a steady decrease in conductivity $\kappa$ with increasing mass fraction of the starch, and also a monotonous increase in $\kappa$ with temperature. The experimental data (values of conductivity from 32 experiments) can be approximated with acceptable accuracy by the Lorenz formula as a function of temperature and mass fraction

$$
\kappa=\frac{\kappa_{0}}{\left[1+\left(\frac{T-T_{1}}{T_{2}}\right)^{2}\right] \cdot\left[1+\left(\frac{\omega-\omega_{1}}{\omega_{2}}\right)^{2}\right]},
$$

where parameters $\kappa_{0}, T_{1}, T_{2}, \omega_{1}, \omega_{2}$, shown in the first row of Table 2, were identified by regression analysis using Sigma Plot software. The accuracy of formula (2) can be estimated to about $10 \%$, compared with the data for the electric conductivity of tap water presented by Metaxas [16].

Table 2: Coefficients of the Lorentz relationship (2)

\begin{tabular}{|c|c|c|c|c|c|c|}
\hline$\omega$ range & $\begin{array}{c}T \text {-range } \\
\left({ }^{\circ} \mathrm{C}\right)\end{array}$ & $\begin{array}{c}\kappa_{0} \\
\left(\mathrm{~S} \cdot \mathrm{m}^{-1}\right)\end{array}$ & $\omega_{1}$ & $\omega_{2}$ & $\begin{array}{c}T_{1} \\
\left({ }^{\circ} \mathrm{C}\right)\end{array}$ & $\begin{array}{c}T_{2} \\
\left({ }^{\circ} \mathrm{C}\right)\end{array}$ \\
\hline $0.05-0.35$ & $20-90$ & 0.087 & 0.0783 & 0.4122 & 92.84 & 63.84 \\
\hline $0.55-0.65$ & $25-100$ & 64.18 & 0.4257 & 0.00254 & 93.64 & 94.17 \\
\hline
\end{tabular}

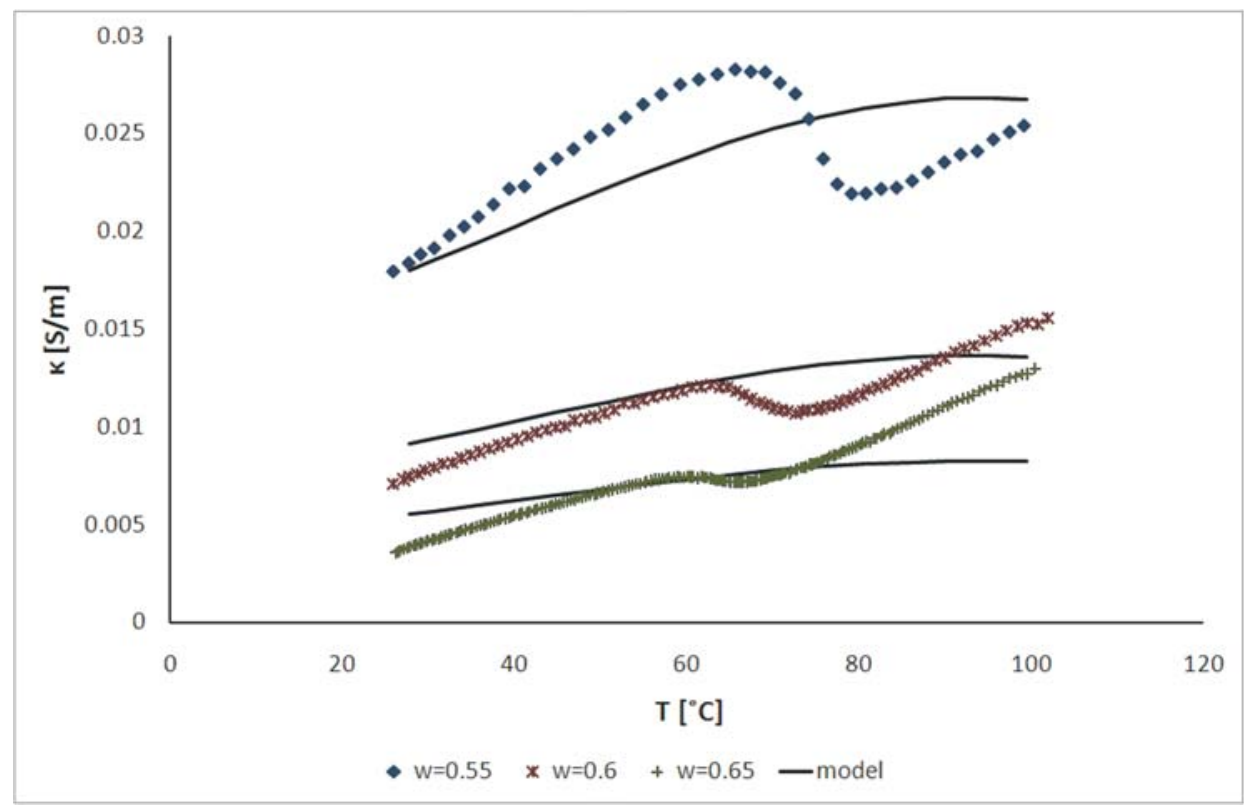

Fig. 2: Electric conductivity (experimental data and Eq. (2)) for mass fractions of potato starch $\omega=0.55,0.6,0.65$ 
Results for higher mass fractions of starch (0.55 to 0.65$)$ were obtained from experiments in a closed cell, corresponding to the technology for thermal forming of a cylindrical sample of starch paste located between two planar stainless steel electrodes (fed by a higher voltage, typically $100 \mathrm{~V}$, at $50 \mathrm{~Hz}$ ). A cross section of this ohmic cell is shown in the right part of Fig. 1. A constant initial mass of starch paste $(50 \mathrm{~g})$ was applied in all experiments, and the corresponding contact surface $S$ was calculated from the density (see Table 1) and the distance of the electrodes $H=10 \mathrm{~mm}$, giving $S=0.00411 \mathrm{~m}^{2}$ at $\omega=0.55$ and $S=0.00397 \mathrm{~m}^{2}$ at $\omega=0.65$. The effective electric conductivity was evaluated using Eq. (1) with the calibration constant $C=H / S$, as follows from the assumption that the intensity of the electric field $(=U / H)$ inside the heated sample is uniform. The electric conductivity was evaluated continuously during heating at approximately constant voltage $U$, recorded together with the electric current $I$ by the LMG-95 powermeter. At the same time, a continuous increase in temperature at the center of the sample was recorded by a T-type thermocouple, which was electrically separated using an insulated amplifier. The thermometer enabled not only assignment of a temperature to the corresponding electric conductivity, but also estimation of the specific electrical conductivity from a simplified enthalpy balance. The results, specific electrical conductivities, are presented in Fig. 2.4

A characteristic feature of temperature courses is a temporary decrease in electric conductivity (typical S-shape), at around $(60-80)^{\circ} \mathrm{C}$, which manifests starch gelatinization. A temporary decrease in electric conductivity during gelatinization is also manifested by peaks of electric power during continuous heating (Fig. 3). The experimental data was approximated by Eq. (2) with the parameters in the second row of Table 2, see Fig. 2. It is obvious that the local conductivity decrease cannot be described by this simple correlation.
Experiments carried out in the ohmic heating cell are in fact feasibility tests of the assumed technology for combined (direct and indirect) ohmic heating. The tests revealed the limits of direct ohmic heating, represented by a significant reduction in effective electric conductivity due to the formation of an insulating steam cushion. The effect of insulating steam was confirmed by experiments, when the power supply was switched off temporarily within the evaporation phase (to let the steam run out) and switched on again. After switching the power supply on, the electric power returns almost to the original high value (slightly lower, the decreasing peak values of the electric power correspond to the decreasing moisture of the gel). The reduction in delivered electric power during evaporation of the water is clearly shown in Fig. 3.

A comparison mass of the samples at the beginning and at the end of the heating process gives the amount of evaporated water. These values, together with the estimated specific heat capacity evaluated from the recorded time profiles of the temperature, are summarized in Table 3. Some preliminary conclusions can be derived from the table: direct ohmic heating can accelerate only the first stage of heating, and cannot be used alone, without simultaneous heating by the hot wall of the mold. The product manufactured using only direct ohmic heating has properties different from those induced by indirect heating in a closed mold: this product is compact, without pores, hard and tough.

Similar conclusions were obtained from experiments with microwave heating of a potato starch suspension in an ohmic cell inserted into a microwave oven (the cell is made from plastic, therefore only the electrodes had to be removed). Although a slightly greater amount of water was evaporated, the mechanical properties of the products were unsuitable, due to the absence of a crust, and the process could not be completed due to problems with local overheating (burnout).

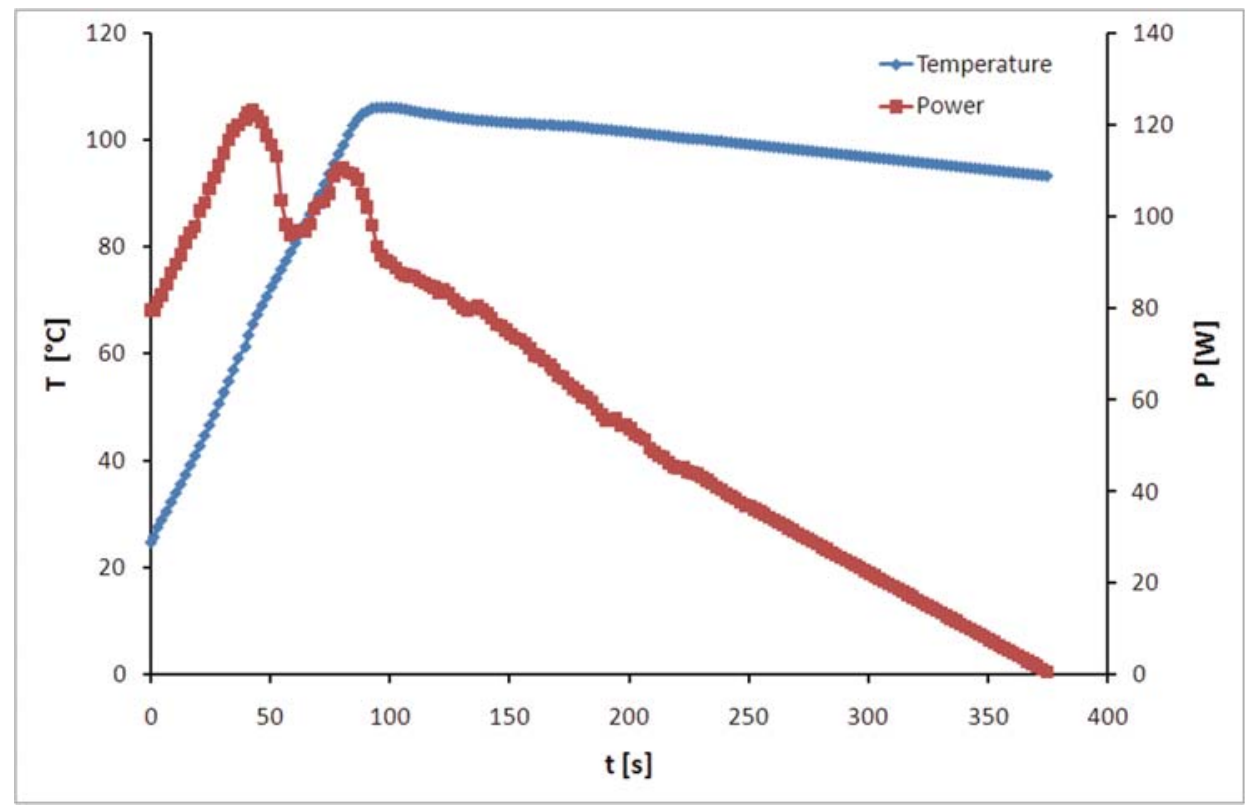

Fig. 3: Time course of temperature and electric power, corresponding to a constant feeding voltage $U=100 \mathrm{~V}$, initial mass $50 \mathrm{~g}$, mass fraction of starch $\omega=0.55$ 
Table 3: Summary of the experiments using direct ohmic heating of a starch suspension

\begin{tabular}{|c|c|c|c|c|}
\hline$\omega$ & $\begin{array}{c}\text { ratio of evaporated water } \\
\text { (measured) }\end{array}$ & $\begin{array}{c}\text { specific heat capacity } \\
\left.\text { (median } 25^{\circ} \mathrm{C}-60^{\circ} \mathrm{C}\right)\end{array}$ & $\begin{array}{c}\text { process time } \\
\text { from } 25^{\circ} \mathrm{C} \text { up to } 90^{\circ} \mathrm{C}\end{array}$ & $\begin{array}{c}\text { process time corresponding to } \\
\text { indirect heating } \\
\left.\text { (wall temperature } 180{ }^{\circ} \mathrm{C}\right) \\
\text { Estimated from model Skocilas [12] } \\
(\mathrm{s})\end{array}$ \\
\hline 0.55 & 18.67 & $1815 \pm 235$ & 65 & 70 \\
\hline 0.6 & 11.90 & $1690 \pm 230$ & 141 & 68 \\
\hline 0.65 & 7.31 & $1562 \pm 231$ & 378 & 66 \\
\hline
\end{tabular}

\section{Properties of manufactured sandwich plates}

Thermal processing of potato starch (and related material properties) is one thing, another thing are the properties of the manufactured products, foam sandwich plates with a crust. The most important parameter is the porosity of the foam, and this must be known not only for modeling the production processes (expansion inside a mold). Porosity determines all the mechanical properties and the thermal insulation capacity of the products. The higher the porosity, the lower is the thermal conductivity (the better is the insulation). The mechanical properties fall, but this can be compensated by higher strength of the crust. There are several practical questions that should be answered: Can we assume that the porosity is uniform throughout the sample, even if it expands inside the mold several times? What factors affect porosity: the thickness of the plate, the initial mass fraction of the starch, the temperature of the mold? Is it possible to determine the porosity of the product from the thermal conductivity measurement, and vice versa? Similar questions concern the thickness of the crust: Is it independent of the thickness of the manufactured sandwich plate, etc. Some of these questions are discussed in this section, which analyses the properties of sandwich plates manufactured from Naturamyl potato starch (mass fraction of starch $\omega=0.5$ ) in a mold with electrically heated walls (maintained at constant temperature $180^{\circ} \mathrm{C}$ ). A schematic representation of the apparatus is shown in Fig. 4.

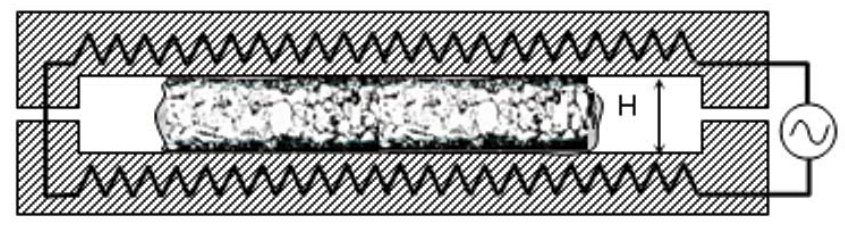

Fig. 4: Indirectly heated mold ( $H=4$ and $8 \mathrm{~mm}$, cavity $200 \times 270 \mathrm{~mm}$ )

The manufactured products were plates, corresponding to dimensions of the cavity $200 \mathrm{~mm} \times 270 \mathrm{~mm} \times \mathrm{H}$, where thickness $\mathrm{H}$ was adjusted to 4 and $8 \mathrm{~mm}$ alternatively. The volume of the starch suspension poured onto the bottom of the mold at the beginning of the experiment was approximately 3 times less than the volume of the cavity (the corresponding porosity of the manufactured plate should be according to this $\mathrm{e}=1 / 3$, but this is only an approximation, because a part of the expanded foam escapes through the venting slits and, above the density of the suspension differs from the density of thermally processed starch).

\subsection{Thermal conductivity}

The thermal conductivity of the samples was measured using a Kemtherm thermal conductivity meter QTM-3 (Kyoto Electronics). A probe in the form of a thin ohmically heated metallic band is applied to the surface of the sample, and thermal conductivity 1 is evaluated from the recorded time course of the band temperature (this is in principle a transient heated wire method). Since the QTM-3 instrument requires

Table 4: Thermal conductivity of processed sandwiches (thicknesses $H=4$ and $8 \mathrm{~mm}$ )

\begin{tabular}{|c|cc|cc|}
\hline \multirow{2}{*}{$\begin{array}{c}\text { No. } \\
\text { off measurement }\end{array}$} & \multicolumn{2}{|c|}{$\begin{array}{c}\text { Thickness } H=8 \mathrm{~mm} \\
\lambda\left(\mathrm{W} \cdot \mathrm{m}^{-1} \cdot \mathrm{K}^{-1}\right)\end{array}$} & \multicolumn{2}{c|}{$\begin{array}{c}\text { Thickness } H=4 \mathrm{~mm} \\
\lambda\left(\mathrm{W}^{-1} \cdot \mathrm{K}^{-1}\right)\end{array}$} \\
\cline { 2 - 5 } & boundary & center & 0.0696 & center \\
\hline 1 & 0.0693 & 0.0774 & 0.0708 & 0.07 \\
2 & 0.0693 & 0.0773 & 0.0667 & 0.0692 \\
3 & 0.0694 & 0.0766 & 0.0691 & 0.0696 \\
4 & 0.0688 & 0.0767 & 0.0685 & 0.0698 \\
5 & 0.0691 & 0.0761 & $\mathbf{0 . 0 6 9} \pm \mathbf{0 . 0 0 1 5}$ & $\mathbf{0 . 0 7 0} \pm \mathbf{0 . 0 0 0 4 1}$ \\
\hline mean value & $\mathbf{0 . 0 6 9} \pm \mathbf{0 . 0 0 0 2 4}$ & $\mathbf{0 . 0 7 7 \pm 0 . 0 0 0 5 4}$ & &
\end{tabular}


sufficiently thick samples, at least three plates had to be stacked on at measurement with thin plates $H=4 \mathrm{~mm}$. A thermal conductivity map was obtained when the probe was moved along the surface, and Table 4 shows the results (the values at the center and at the border of the plate represent 5 repeated measurements at each point). The data indicate that the thermal conductivity is almost independent of the sandwich thickness, at least within the accuracy of measurement, and also the lateral changes are not very significant (only about a $10 \%$ decrease at the boundary was observed for $H=8 \mathrm{~mm}$ ). Similar results were reported by Žitný [17] for plates also manufactured from potato starch but at a lower initial mass fraction $\omega=0.4$. The mean thermal conductivity value for $H=4 \mathrm{~mm}$ was $\lambda=0.066 \mathrm{~W} \cdot \mathrm{m}^{-1} \cdot \mathrm{K}^{-1}(\lambda=0.067$ at the centre and $\lambda=0.063$ at a corner of plate).

The QTM-3 conductivity meter is designed for measuring homogeneous samples. However, the sandwich plates are not homogeneous and the conductivities reported in Table 4 are only mean conductivities affected by the different conductivities of the foam (in the core) and the crust.

The thermal conductivity of foam $\lambda_{\mathrm{f}}$ depends on porosity $\varepsilon_{\mathrm{f}}$. Assuming a uniform arrangement of spherical pores in a cubic grid, thermal conductivity $\lambda_{\mathrm{f}}$ can be expressed by

$\frac{\lambda_{\mathrm{f}}}{\lambda_{\mathrm{s}}}=1-\pi\left(\frac{3 \varepsilon_{\mathrm{f}}}{4 \pi}\right)^{\frac{2}{3}}\left[1-\frac{3 \frac{\lambda_{\mathrm{a}}}{\lambda_{\mathrm{s}}}-\left(\frac{8 \sqrt{2}}{\pi} \sqrt[3]{\frac{3 \varepsilon_{\mathrm{f}}}{4 \pi}}-2\right)\left(1-\frac{\lambda_{\mathrm{a}}}{\lambda_{\mathrm{s}}}\right)}{2+\frac{\lambda_{\mathrm{a}}}{\lambda_{\mathrm{s}}}}\right]$

where $\lambda_{\mathrm{s}}$ is the thermal conductivity of the starch matrix and $\lambda_{\mathrm{a}}$ is the conductivity of the air inside the pores. This relationship follows from the analytical solution of the temperature field around a single sphere $\left(\lambda_{\mathrm{a}}\right)$, which is surrounded by an infinite medium having conductivity $\lambda_{\mathrm{s}}$. Therefore the result is valid only for relatively small porosities, $\varepsilon_{\mathrm{f}}<0.5$. Relationship (3) can be approximated by a linear asymptote, corresponding to the case of two parallel resistors (parallel channels of air and starch).

$$
\frac{\lambda_{\mathrm{f}}}{\lambda_{\mathrm{s}}}=1-\varepsilon_{\mathrm{f}}\left(\frac{\lambda_{\mathrm{a}}}{\lambda_{\mathrm{s}}}\right) .
$$

Using Eq. (4), the following expression for the mean thermal conductivity $\lambda$ can be derived (summing the thermal resistances of compact crust and foam)

$$
\begin{aligned}
\frac{\lambda_{\mathrm{s}}}{\lambda}=h^{*}+\frac{\lambda_{\mathrm{s}}}{\lambda_{\mathrm{f}}}\left(1-h^{*}\right) & \cong h^{*}+\frac{1-h^{*}}{1-\varepsilon_{\mathrm{f}}\left(1-\frac{\lambda_{\mathrm{a}}}{\lambda_{\mathrm{s}}}\right)} \\
& =h^{*}+\frac{1-h^{*}}{1-\frac{\varepsilon}{1-h^{*}}\left(1-\frac{\lambda_{\mathrm{a}}}{\lambda_{\mathrm{s}}}\right)},
\end{aligned}
$$

where $h^{*}$ is the relative thickness of an idealized compact crust without pores, and $\varepsilon=\varepsilon_{\mathrm{f}}\left(1-h^{*}\right)$ is the mean porosity of the whole sandwich plate. Eq. (5) can be used for an evaluation of porosity from the measured mean thermal conductivity of plate $\lambda$, or conversely for an evaluation of the thermal conductivity of the starch matrix $\lambda$ s from measured porosity $\varepsilon$. A problem is that the accuracy of Eq. $(3,4)$ decreases with increasing porosity. Results for porosity $\varepsilon$ greater than 0.7 (and this is the typical porosity of manufactured sandwiches) are unreliable. Eq. (5) was applied only for an evaluation of thermal conductivity $\lambda_{\mathrm{s}}$ from the results obtained with mechanically compressed sandwiches (see next section). These plates were characterized by reduced porosity $\varepsilon=0.54$, thermal conductivity of sample $\lambda=0.09 \mathrm{~W} \cdot \mathrm{m}^{-1} \cdot \mathrm{K}^{-1}$ $\left(\lambda_{\mathrm{a}}=0.025 \mathrm{~W} \cdot \mathrm{m}^{-1} \cdot \mathrm{K}^{-1}\right)$, giving $\lambda_{\mathrm{s}}=0.167$ for $\mathrm{h}^{*}=0$ and $\lambda_{\mathrm{s}}=0.175 \mathrm{~W} \cdot \mathrm{m}^{-1} \cdot \mathrm{K}^{-1}$ for $h^{*}=0.1$.

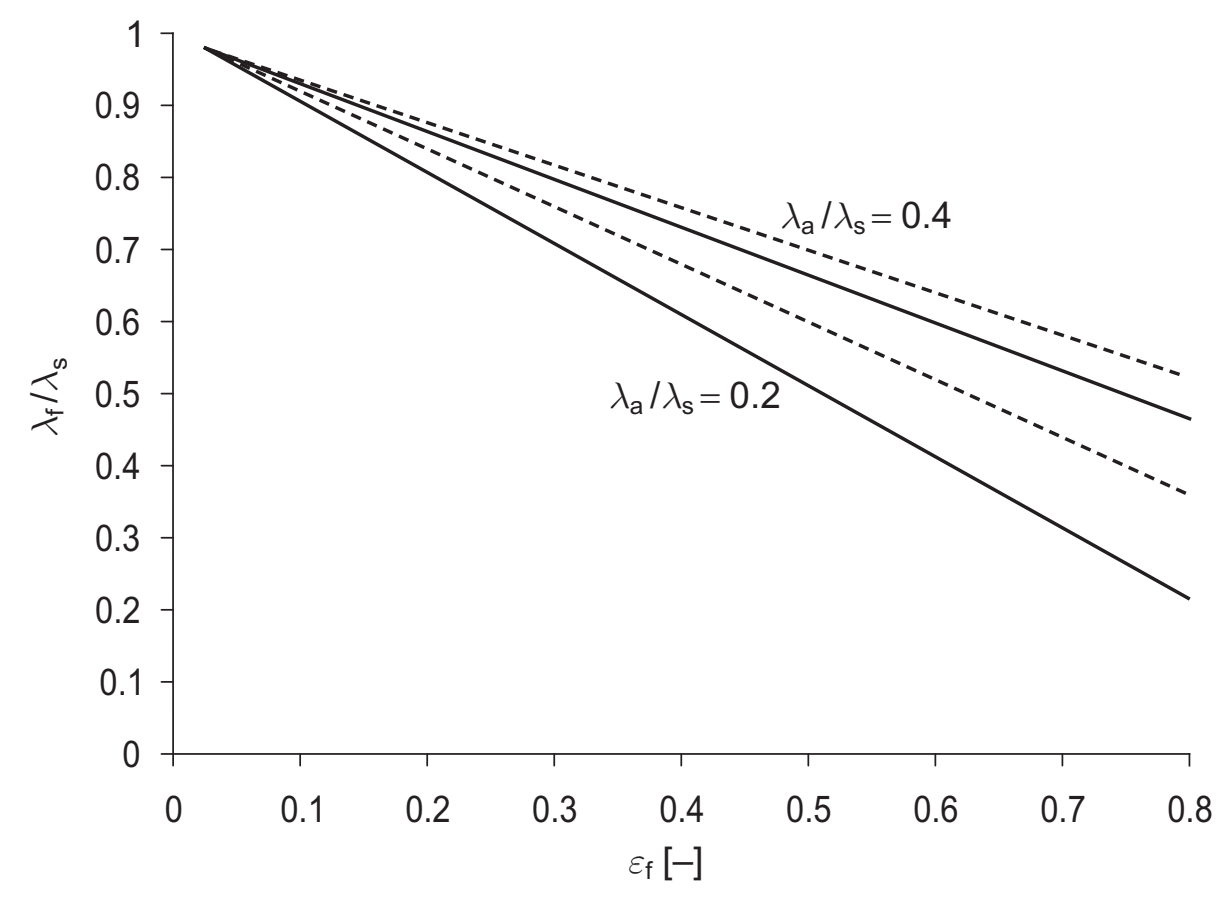

Fig. 5: Temperature conductivity of foam as a function of the porosity of foam (dotted lines are linear asymptotes) 


\subsection{Porosity and crust}

Porosity was determined in two ways, first by compressing the sandwich plates in a hydraulic press, giving the relationship between the load (acting force) and the reduced thickness of the sample. At a sufficiently great force, the thickness became almost independent of the load, and it can be assumed that the compacted sandwich had approximately zero porosity. Comparing the final volume of the compacted sandwich with the initial volume, the porosity can be evaluated. When the cross-section of the hydraulic press clamps was large (rectangular contact surface $60 \times 30 \mathrm{~mm}$ and the tested sandwich plates exceeded this surface), it was assumed that the lateral expansion is small and therefore the volume reduction was calculated only from the displacement of the clamps. The results presented in table 6 agree quite well with previously obtained results for a lower mass fraction of starch $\omega=0.4$, when mean porosity was also 0.7 , Žitný [17]. The thermal conductivity of the compacted plates was measured, and is compared with the thermal conductivity of the foamed plates in Tab. 4. This experimental technique has a drawback caused by a slight relaxation of the sample after removal of the load (for example initial thickness $H=8 \mathrm{~mm}$ was reduced to $2.38 \mathrm{~mm}$ after compression and relaxed to $3.63 \mathrm{~mm}$ when unloaded). The thermal conductivities could be measured only with these relaxed samples, and not with compacted samples.

The second technique applied for evaluating the porosity and crust was image analysis of photographs of cross-sections of the plates. The cross sections were prepared from cuts, polished to a perfect plane with sandpaper, and coloured by black ink so that the structure just at the plane of the cut would be accentuated. Digital photographs were processed by NIS-Elements BR 3.0 software. Thresholding was carried out in a standard way by selecting a suitable cubic subset of points in the RGB space, and the selected mask was applied to all processed photographs. An example of such a processed photograph is shown in Fig. 6.

Fig.6 is a bitmap with 1408 pixels in the $x$-direction (along the plate, the corresponding physical size is $L=27.74 \mathrm{~mm}$ ), and 256 pixels in the $y$-direction (transversal profile for thickness of plate $H=4 \mathrm{~mm}$ ). White pixels represent the starch matrix, black pixel an empty space. Histograms (sums of black pixels counts $c_{\mathrm{H}}(x)$ and $c_{\mathrm{L}}(y)$ along the columns and rows of the bitmap) characterize the porosity variation across the thickness $\left(c_{\mathrm{L}}(y)\right)$ and along the plate $\left(c_{\mathrm{H}}(x)\right)$. This bitmap illustrates some undesirable effects, for example non-uniform illumination (the right side is overexposed) and a small depression of the upper surface. In such a case, the bitmaps have to be corrected manually by excluding the distorted columns from the statistical evaluation (in this case, columns 400 to 600 and above 1300, were extracted). The mean porosity was evaluated simply as the relative number of black pixels in the bitmap. The crust is characterized by increased values of $c_{\mathrm{L}}(y)$ at bottom and top, but the interface is not sharp and a suitable algorithm must be designed capture the interface. The bottom and the head part were analysed separately, and in each part the histogram $c_{\mathrm{L}}(y)$ was approximated by the function

$$
c_{\mathrm{L}}(y)=c_{1}+c_{2} \tanh \left(\frac{y-y_{c}}{\Delta}\right),
$$

where $y$ is the distance from the surface and $y_{c}$ is the unknown position of the interface (thickness of the crust). Parameters $y$, $y_{c}$ and $\Delta$ can be substituted by integers - the number of pixels for simplicity. Parameters $c_{1}, c_{2}, y_{c}$ were identified by regression analysis, using the least squares criterion. Assuming $\Delta=1$ (narrow interface), the linear parameters $c_{1}, c_{2}$ are given as

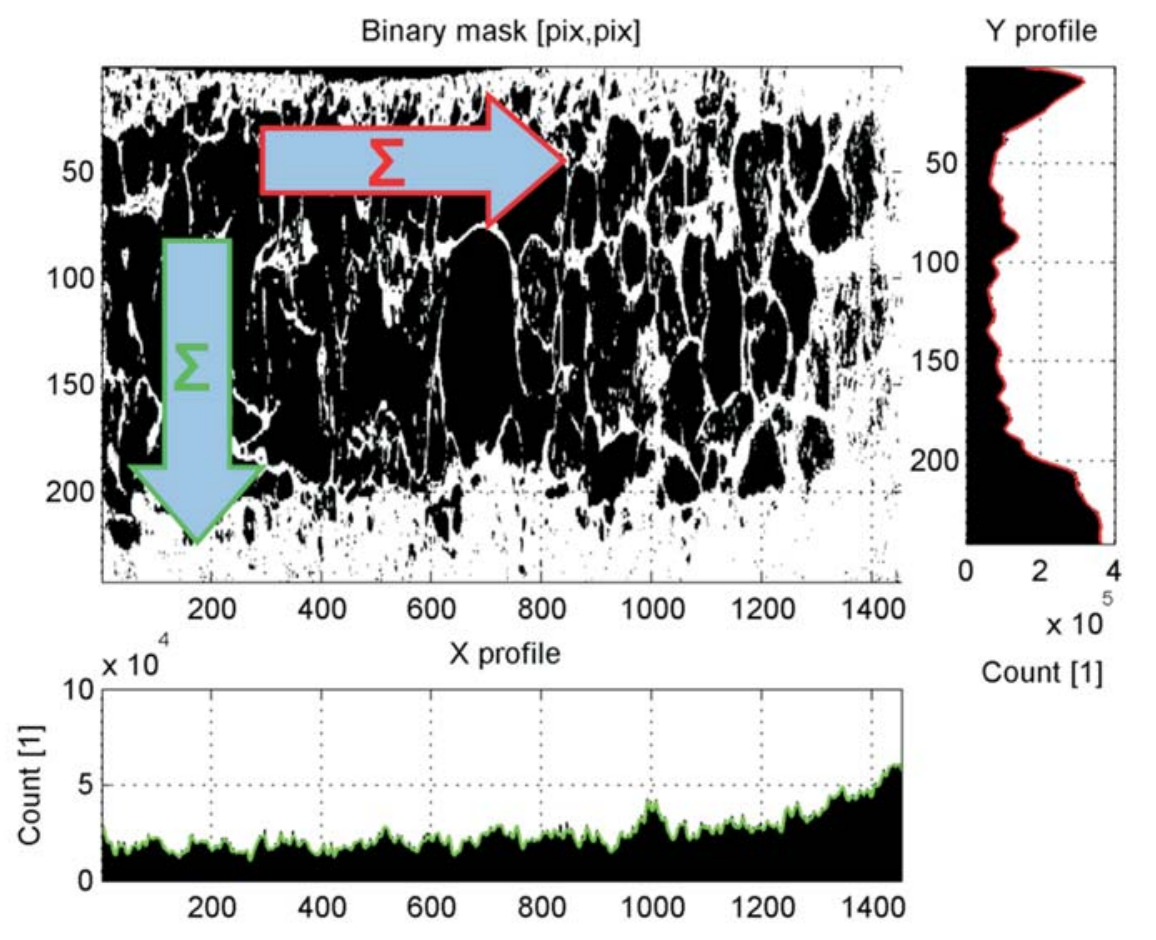

Fig. 6: Bitmap of cross section $H=4 \mathrm{~mm}$ 


$$
\begin{aligned}
c_{1} & =\frac{\sum c_{\mathrm{L}}\left(y_{i}\right) \sum \tanh ^{2}\left(y_{i}-y_{c}\right)-\sum c_{\mathrm{L}}\left(y_{i}\right) \tanh \left(y_{i}-y_{c}\right) \sum \tanh \left(y_{i}-y_{c}\right)}{N \sum \tanh ^{2}\left(y_{i}-y_{c}\right)-\left(\sum \tanh \left(y_{i}-y_{c}\right)\right)^{2}}, \\
c_{2} & =\frac{N \sum c_{\mathrm{L}}\left(y_{i}\right) \tanh \left(y_{i}-y_{c}\right)-\sum c_{\mathrm{L}}\left(y_{i}\right) \sum \tanh \left(y_{i}-y_{c}\right)}{N \sum \tanh ^{2}\left(y_{i}-y_{c}\right)-\left(\sum \tanh \left(y_{i}-y_{c}\right)\right)^{2}},
\end{aligned}
$$

where $N$ is the number of pixels in the selected part of the histogram. The nonlinear parameter $y_{c}$ was identified by a linear search, so that the criterion $s^{2}$ was minimized

$$
s^{2}\left(y_{c}\right)=\sum_{i=1}^{N}\left(c_{\mathrm{L}}\left(y_{i}\right)-c_{1}-c_{2} \tanh \left(y_{i}-y_{c}\right)\right)^{2} .
$$

This approach has the advantage of simplicity and it works without some artificial smoothing of $c_{\mathrm{L}}(y)$ (the smoothing is realized in fact by the hyperbolic tangents (6)). The algorithm is insensitive to "outlier points" and overcomes problems with local extremes of $c_{\mathrm{L}}(y)$. Examples of results obtained by this approach are shown in Table 5 . It is obvious that the identified layers of crust are not homogeneous, the layers are porous and the upper layer is usually not so compact as the bottom layer. A better characteristic of the layers from point of view of thermal resistance is therefore reduced thickness of an equivalent compact layer. The thickness of this compact layer is evaluated from the requirement that the amount of starch (counts of white pixels) is the same as in the "geometrically" determined porous crust $y_{c}$.

This size of the pores in the foam was only estimated by analyzing rows of bitmaps in the central region, with the ex- ception of crust layers. Contiguous parts (horizontal sections of black pixels) were considered as a measure of the corresponding pore diameter and were evaluated statistically, giving a rough estimate of the mean and maximum diameter.

All textural properties (porosity and thickness of crust) were evaluated by image analysis of 25 samples for $\mathrm{H}=4 \mathrm{~mm}$ and 24 samples for $\mathrm{H}=8 \mathrm{~mm}$. Each sample was represented by two photographs (two lateral cross sections) and the results are shown in Tab. 6 . The values in parentheses were evaluated from identical bitmaps, but using a quite different processing algorithm, by Hulan [18]. Differences are caused for example by the fact that Hulan also evaluated the overexposed parts of the bitmap (the effect of non-uniform illumination was not corrected). However, these differences do not invalidate the basic conclusions: the porosity is almost independent of the plate thickness, unlike the thickness of the crust. The thickness of the crust is approximately proportional to the thickness of the sandwich plate. The fact that the thickness of the crust at the upper surface is less than the thickness of the crust on the bottom indicates some technological imperfections: the bottom part was heated slightly longer (it takes some time to close the upper lid of the mold) and also the thermal contact with the upper plate was not so good as on the bottom.

Table 5: Thickness of crust, dotted lines $\left(y_{c}\right)$ evaluated from Eq. (8). Examples of evaluation

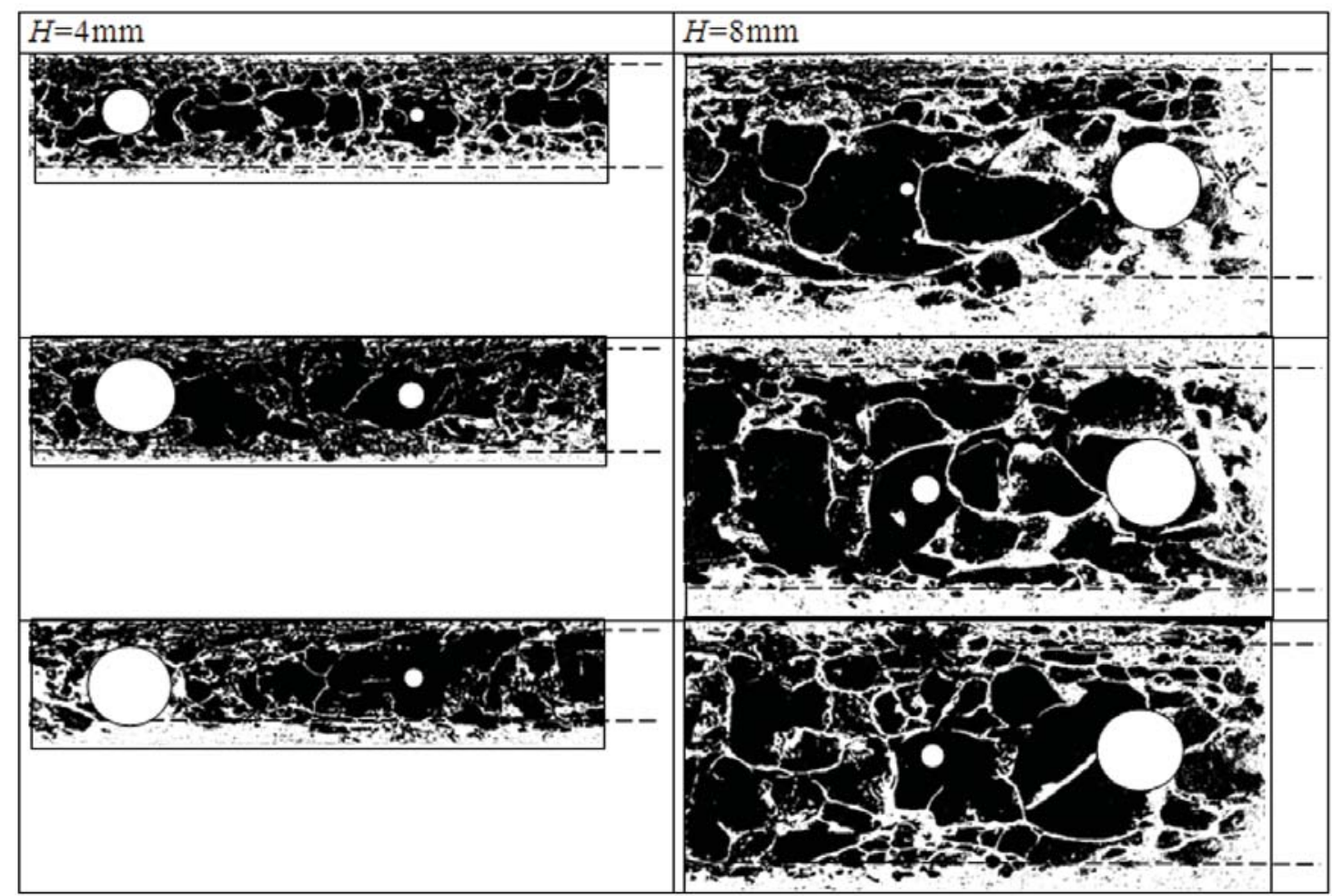


Table 6: Porosity and thickness of the crust $\left(\right.$ values $^{+}$reported by Hulan [19])

\begin{tabular}{|c|c|c|}
\hline & $H=4 \mathrm{~mm}$ & $H=8 \mathrm{~mm}$ \\
\hline \multicolumn{3}{|l|}{ Overall porosity (including crust) } \\
\hline$\varepsilon$ (porosity from compression tests) & 0.69 & 0.7 \\
\hline$\varepsilon$ (porosity by image analysis) & $0.71 \pm 0.05\left(0.68^{+}\right)$ & $0.74 \pm 0.05 \quad\left(0.70^{+}\right)$ \\
\hline \multicolumn{3}{|c|}{ Relative thickness of crust identified from Eq. (8) } \\
\hline$h_{\text {top }} / \mathrm{H}$ & $0.08 \pm 0.04 \quad\left(0.12^{+}\right)$ & $0.13 \pm 0.08 \quad\left(0.12^{+}\right)$ \\
\hline$h_{\text {bottom }} / \mathrm{H}$ & $0.15 \pm 0.04 \quad\left(0.15^{+}\right)$ & $0.12 \pm 0.02 \quad\left(0.16^{+}\right)$ \\
\hline $1-h / H$ (relative thickness of porous core) & $0.77 \pm 0.05 \quad\left(0.73^{+}\right)$ & $0.76 \pm 0.08 \quad\left(0.72^{+}\right)$ \\
\hline$h_{\text {top }}^{*}($ compacted crust $/ H)$ & $0.04 \pm 0.01$ & $0.05 \pm 0.02$ \\
\hline$h_{\text {bottom }}^{*}($ compacted crust $/ H)$ & $0.11 \pm 0.03$ & $0.09 \pm 0.02$ \\
\hline \multicolumn{3}{|l|}{ Diameter of pore } \\
\hline \multicolumn{3}{|l|}{$D_{\text {mean }}[\mathrm{mm}]$} \\
\hline$D_{\max }[\mathrm{mm}]$ & $2.26 \pm 0.41$ & $3.52 \pm 1.04$ \\
\hline
\end{tabular}

\section{Discussion}

Experiments carried out with direct ohmic heating and microwave heating of a concentrated suspension of potato starch indicate that volumetric heating alone is not able to evaporate a sufficient amount of water, due to increased electrical resistance (in the case of direct ohmic heating), or due to local overheating (in the case of microwaves). The electrical properties of a starch suspension were therefore evaluated only in a reduced temperature range up to $100^{\circ} \mathrm{C}$. Volumetric heating can be used only as an auxiliary tool during the initial process stages, and must be combined with indirect heating from the walls. Another disadvantage of volumetric heating is the absence of a crust, which is important for the mechanical and stability properties of the final products. On the other hand the technology for baking plates, containers, etc., from potato-starch water suspensions (+additives like fibres, $\mathrm{CaCO}_{3}$ ) that is applied in practice, consists of two stages, Glenn et al. [1]: the first stage is preparation of the starch suspension, preheating and forming the gel, and then the gelatinized starch is baked to the final form. It seems that direct ohmic heating is more suitable for the first stage, and the evaluated electrical properties provide a sufficient background for the design.

Experiments carried out with manufactured potato starch foams confirm that the porosity and thermal conductivity of sandwich plates prepared by standard indirect heating is almost independent of the thickness of the plates. Values of porosity evaluated by quite independent techniques (by image analysis and by compression tests) are in accordance with the results obtained by thermal conductivity measurements. It seems that thermal conductivity measurements could be a fast way to check the uniformity and of the current porosity values of manufactured products. However, it is somewhat surprising that the measured values $\lambda$ are not affected by the crust, which seems to be the only parameter depending on the plate thickness. Image analysis of the cross section reveals that the thickness of the crust is approximately proportional to the thickness of the manufactured plates (of course, it is difficult to reach a more specific conclusion, because only plates $H=4$ and $8 \mathrm{~mm}$ were analyzed). Most of the questions formulated in section 4 still remain: it is not known how porosity and the crust are affected by the composition of suspension and by the wall temperature.

\section{List of symbols}

c specific heat capacity $\left(\mathrm{J} \cdot \mathrm{kg}^{-1} \cdot \mathrm{K}^{-1}\right)$

$c_{\mathrm{L}} \quad$ counts of pixels in a row of bitmap (-)

$c_{\mathrm{H}} \quad$ counts of pixels in a column of bitmap (-)

$c_{1}, c_{2} \quad$ parameters of regression function

C calibration constant

$D_{\text {mean }}, D_{\text {max }}$ mean and maximum pore diameter $(\mathrm{mm})$

$H \quad$ distance of electrodes (m)

$H \quad$ sample thickness (m)

$h^{*} \quad$ dimensionless thickness of crust

I electrical current (A)

$K \quad$ consistency coefficient $\left(\mathrm{Pa} \cdot \mathrm{s}^{\mathrm{n}}\right)$

$n \quad$ flow index behavior (-)

$N \quad$ number of pixels (-)

$S \quad$ area $\left(\mathrm{m}^{2}\right)$

$t \quad$ time (s)

T temperature $\left({ }^{\circ} \mathrm{C}\right)$

$T_{1}, T_{2} \quad$ parameters in Eq. $(2)\left({ }^{\circ} \mathrm{C}\right)$

$U \quad$ voltage $(\mathrm{V})$

$X \quad$ relative moisture $(\mathrm{kg}$ water $/ \mathrm{kg}$ solid $)$

y distance from surface $(\mathrm{m})$

$\varepsilon \quad$ porosity of sandwich plate (-)

$\varepsilon_{\mathrm{f}} \quad$ porosity of foam in the core of sandwich plate $(-)$

$\kappa \quad$ specific electrical conductivity $\left(\mathrm{S} \cdot \mathrm{m}^{-1}\right)$

$\lambda \quad$ thermal conductivity of porous layer $\left(\mathrm{W} \cdot \mathrm{m}^{-1} \cdot \mathrm{K}^{-1}\right)$ 


$\begin{array}{ll}\lambda_{\mathrm{a}} & \text { thermal conductivity of air }\left(\mathrm{W} \cdot \mathrm{m}^{-1} \cdot \mathrm{K}^{-1}\right) \\ \lambda_{\mathrm{f}} & \text { thermal conductivity of foam }\left(\mathrm{W} \cdot \mathrm{m}^{-1} \cdot \mathrm{K}^{-1}\right) \\ \lambda_{\mathrm{s}} & \text { thermal conductivity of } \mathrm{starch} \text { matrix } \\ & \left(\mathrm{W} \cdot \mathrm{m}^{-1} \cdot \mathrm{K}^{-1}\right) \\ \rho & \text { density }\left(\mathrm{kg} \cdot \mathrm{m}^{-3}\right) \\ \rho_{\mathrm{S}} & \text { density of starch }\left(\mathrm{kg} \cdot \mathrm{m}^{-3}\right) \\ \omega & \text { mass fraction of starch (-) } \\ \omega_{1}, \omega_{2} & \text { parameters in Eq. (2) (-) }\end{array}$

\section{Acknowledgment}

This research has been supported by the Grant Agency of the Czech Republic, project 101/06/0535.

\section{References}

[1] Glenn, G. M., Orts, W. J., Nobes, G. A. R.: Starch, Fiber and $\mathrm{CaCO}_{3}$ Effects on the Physical Properties of Foams Made by a Baking Process. Industrial Crops and Products, Vol. 14 (2001), p. 201-212.

[2] Zanoni, B., Smaldone, D., Schiraldi, A.: Starch Gelatinization in Chemically Leavened Bread Baking. Journal of Food Science, Vol. 56 (1991), No. 6, p. 1702.

[3] Wang, J., Hayakawa, K.: Thermal Conductivities of Starch Gels at High Temperatures Influenced by Moisture. Journal of Food Science, Vol. 58 (1993), No. 2.

[4] Maroulis, Z. B., Drouzas, A. E., Saravacos, G. D.: Modelling of Thermal Conductivity of Granular Starches. Journal of Food Engineering, Vol. 11 (1990), p. 255-271.

[5] Lind, I., Rask, C.: Sorption Isotherms of Mixed Meat, Dough and Bread Crust. Journal of Food Engineering, Vol. 14 (1991), p. 303-315.

[6] Cha, J. Y., Chung, D. S., Seib, P. A., Flores, R. A., Hanna, M. A.: Physical Properties of Starch-Based Foams as Affected by Extrusion Temperature and Moisture Content. Industrial Crops and Products, Vol. 14 (2001), p. 23-30.

[7] Schwarzberg, H. G.,Wu, J. P. C, Nussinovitch, A., Mugerwa, J.: Modelling Deformation and Flow during Vapor-Induced Puffing. Journal of Food Engineering, Vol. 25 (1995), p. 329-372.

[8] Wang, W. Ch., Sastry, S. K.: Starch Gelatinization in Ohmic Heating. Journal of Food Engineering, Vol. 34 (1997), p. 225-242.

[9] Lagarrigue, S., Alvarez, G.: The Rheology of Starch Dispersion at High Temperatures and High Shear Rates: a Review. Journal of Food Engineering, Vol. 50 (2000), p. 189-202.

[10] Shogren, R. L., Lawton, J. W., Tiefenbacher, K. F.: Baked Starch Foams: Starch Modifications and Additives Improve Process Parameters, Structure and
Properties. Industrial Crops and Products, Vol. 16 (2002), p. 69-79.

[11] Zanoni, B., Peri, C., Pierucci, S.: A Study of the Bread Baking Process. I: A Phenomenological Model.Journal of Food Engineering, Vol. 19 (1993), p. 389-398.

[12] Skočilas, J., Žitný, R.: Thermal Pressure Forming of Food Materials In: $17^{\text {th }}$ International Congress of Chemical and Process Engineering [CD-ROM]. Prague: Czech Society of Chemical Engineering, 2006, p. 1-9. ISBN 80-86059-45-6.

[13] Wu, Y., Irudayaraj, J.: Analysis of Heat, Mass and Pressure Transfer in Starch Based Food Systems. Journal of Food Engineering, Vol. 29 (1996), p. 399-414.

[14] Fan, J., Mitchell, J. R., Blanshard, J. M. V.: A Computer Simulation of the Dynamics of Bubble Growth and Shrinkage during Extrudate Expansion. Journal of Food Engineering, Vol. 23 (1994), p. 337-356.

[15] Parker, R., Ollett, A. L, Lai-Fook, R. A., Smith, A. C.: The Rheology of Food Melts and its Application in Extrusion Processing. Rheology of Food Biological and Pharmaceutical Materials, R.E. Carter. London: Elsevier, 1989.

[16] Metaxas, A. C.: Foundations of Electroheat. Chichester: Willey, 1996. ISBN 0-471-95644-9.

[17] Žitný, R.: Waffle Baking, part VIII, Experiments. Research report CTU FME, Prague 1999.

[18] Hulan, M. : Image analysis of a porous layer (in Czech), Internal report, CTU FME, 2008.

Ing. Jaromír Štancl

phone: +420224352719

Fax: +420224310292

e-mail: jaromir.stancl@fs.cvut.cz

Ing. Jan Skočilas

phone: +420 224352719

Fax: +420224310292

e-mail: jan.skocilas@fs.cvut.cz

Prof. Ing. Jiřri Šesták, DrSc.

phone: +420224352547

Fax: +42022431029

e-mail: jiri.sestak@fs.cvut.cz

Prof. Ing. Rudolf Žitný, CSc.

phone: +420224352555

Fax: +420224310292

e-mail: rudolf.zitny@fs.cvut.cz

Department of Process Engineering

Czech Technical University in Prague

Faculty of Mechanical Engineering

Technická 4

16607 Prague 6, Czech Republic 